\title{
The Ideas about the Building of Chifeng University North Road
}

\author{
Yunchao Liu, Li Ma, Bo Fang, Rili Cong, \\ ${ }^{1}$ College of resources and environmental science, Chifeng University, Chifeng 024000
}

Liuyunchao616@126.com

Keywords: Financial Street, Hi -tech Industrial Park, Chifeng

\begin{abstract}
Based on the characteristics and layout of high-tech industry, this paper analyzes the factors of Chifeng City, Based on the theory of economic geography and industrial layout, the development ideas and theoretical basis for the development of high and New Technology Industrial Park in Chifeng area, which is the main function of the Chifeng University North Road, a financial Street area are proposed.
\end{abstract}

\section{Introduction}

Nowadays, the growth of regional economy is more and more from scientific and technological progress, and the strategy and position of the development of resource based cities are temporary and unsustainable. As China's nonferrous metals in the country and the country to determine the resources of the mature city, Chifeng city in the development of non-ferrous metal processing industry has unique comparative advantages. But in the next few decades, Chifeng nonferrous metals resources will face the situation of exhaustion. industrial structure echelon form theory and Vernon's product cycle theory and the northeast region part of the city's development history tells us: resource-based cities can not be to the depletion of resources, the situation and then consider the transformation of cities and the adjustment of industrial structure. Therefore, Chifeng should start from now, actively cultivate new and high-tech industry, the high-tech industry as the regional economic development of new economic growth pillar. In order to change the future development of Chifeng City, the situation facing the depletion of resources. The Chifeng University focused on a large number of scientific and technological human resources. Chifeng City, city, Financial Street can use the north road construction, and vigorously promote the various factors of production market, and actively promote the innovation of the system mechanism, and promote the rapid growth of economic health in Chifeng city.

\section{The Survey of Chifeng University North Road, Financial Street}

Chifeng University of North Financial Street is located in Chifeng City, the new land within the red mountain. Four borders: State Road 306 East, West Baoshan Road, South Road, North Street, xilamulun, covering an area of about 52 hectares. The financial Street on the north side is to open in 2014 Wanda city complex, east of State Road 306 is large cargo logistics center, Financial Street West is new, Chifeng City stadium, southwest first Hongshan County residential and ancillary projects in construction, Finance Street in Chifeng College in one of the south is in Chifeng City only a full-time undergraduate colleges and Middle East Inner Mongolia three undergraduate colleges and universities.

\section{The characteristics and location selection factors of high tech industry}

Only the research and development, production and manufacturing, sales and service in three aspects closely together, can realize the benign cycle of economic development, and get the maximum economic benefits of high-tech industry.

The research and development of high-tech industries in the production process of innovation activities. It is the process of promoting the high and new technology through the design and experiment. The production and manufacturing is the research team of R \& D results into physical 
or virtual products. Hi tech products not only have the hardware products, but also the software products with high added value. The sales of high-tech products is complicated and systematic. High tech products' sales characteristics are often the cause of the relevant enterprise agglomeration. Three parts of the high-tech industry, the overall operation is the most ideal state of development. However, due to the existence of some kind of demand or objective conditions, the separation of the layout, the layout of the high-tech industry to bring flexibility.

The economic and social factors, science and technology and production factors, living environment factors are the main factors that affect the layout of high-tech industries.

The main effect of the economic and social factors is a high and new technology industry is the product of the development of the regional economy to a certain degree of, and regional industrial structure evolvement results; the second is the high and new technology industry development must rely on all kinds of economic policy support to ensure its regional and good and fast development. The research and development of the science and technology is a high and new technology industry development important prerequisite, The reduction or even loss of talent flow. The development of high-tech industry, the relevant supporting infrastructure is relatively high requirements. Requires local government to optimize the production environment, infrastructure and living conditions.

\section{Analysis of development conditions of Chifeng University North Road, Financial Street}

The Scientific and technological human resources condition. Due to the accelerated pace of economic and social transformation and upgrading, the labor intensive industries in the past can create huge profits will be replaced by intelligent and technology intensive industries. Its essence is our country by the labor force quantity advantage to the quality superiority direction development. In this process, the human resources of science and technology will become an important factor that can not be ignored in regional development.

There are 24 College of education in Chifeng University. Text, science, engineering, law, medicine and other 10 categories. There are 45 undergraduate and 60 professional and professional. Chifeng University teachers are strong, all kinds of talent structure is more reasonable. Chifeng University also has a large number of senior retired teachers, they have become the Chifeng University science and technology, teaching, innovation and valuable resources. The science and technology human resources reserve resources level by science and technology human resources training index reflect. The cultivation of scientific and technological human resources is mainly depend on education, so the college students and graduate students in the region are the main sources of the scientific and technological human resources.

In June 2012, the east of Inner Mongolia Branch was established in Chifeng College by Inner Mongolia Autonomous Region Institute of science and technology limited liability company. Its purpose is to be proactive and local governments, industry, industrial and docking, integrated the resources and advantages, to carry out scientific and technological research and applied research, to contribute to the regional economic and social development. The Eastern Branch of the will of Chifeng College Talents culture, practice teaching base construction, employment support, provide a platform for the development of high level innovation type, application type, compound type talent development..

The Market condition. Chifeng city is located in the eastern part of Inner Mongolia Province, Hebei Province, Liaoning Province, the western region of China, adjacent to the largest integrated industrial base in North China, Beijing, Tianjin and industrial base and the famous heavy industry base in China - South Central and South industrial base These two industrial bases have strong development strength, through long-term development, to form a complete industrial production system, also to see, these two industrial bases in many cities are facing resource depletion, excess capacity, labor costs and other constraints Chifeng City, as a non ferrous metal resource rich city and the central and western regions, we should take advantage of the broad market to break the bottleneck in the development of the economic development strategy in the Bohai economic zone and revitalize the northeast old industrial base development strategy. Chifeng city in the strengthening of inter provincial cooperation, but also the need to build the basis of Financial Street, 
from now on to develop high-tech industry personnel, support high-tech industry enterprises, and promote the interaction between universities and financial companies.

The Policy. The policy environment directly affects the development of a certain kind of industry in the region, and reflects the basic orientation of the government to regional development. To observe the development of the developed countries, many scholars agree that the policy environment has become an important factor in regional economic development.

On the national level, the Central Committee of the CPC Central Committee on deepening reform of the CPC Central Committee on deepening reform of the eighteen major issues of the CPC Central Committee and the Third Plenary Session of the Central Committee of the Communist Party of China. After the national conference in 2013, the Inner Mongolia Autonomous Region, with the actual situation of the development and deployment of the autonomous region, the development of "8337". This is not only the direction of development of Inner Mongolia, but also the goal of the development of Chifeng city.

The Chifeng "Twelfth Five Year" development plan to develop the scientific and technological talents, as the important technical service force, is one of the important measures to improve the transformation rate of scientific and technological achievements. Vigorously develop the high-tech industry, is a key step to promote the optimization and upgrading of industrial structure in Chifeng city. Accelerate the construction of scientific and technological innovation platform, improve the scientific and technological management system and operation mechanism.

The traffic condition. "To get rich first road," the slogan of the popular, relying on traffic between the region to establish a close contact between the road network. Traffic conditions are one of the important factors that affect the regional economic activities. Through the center of the city of Beijing, Beijing, Shen Chi, Chi white, red bearing, Chao Chi, railway, highway, aviation and other line with Beijing, Tianjin, Shenyang, Hohhot, Chengde, Changchun, Harbin and other to be linked, so as to make full use of the vast market of these cities, to take the great leap forward development opportunities.

The Labor condition. The quality and quantity of the labor force is the key factor to influence the regional development. According to the Chifeng economic development related data, by 2017, the population reached more than 1 million. Population to the city, is the result of the economic development and trends. Along with the rapid development of Chifeng city center city in urbanization, industrialization, information, agriculture and animal husbandry industry, the rapid construction, will attract enough, there is a higher quality of labor resources.

Through observation of some the typical examples, it is not hard to find that the high-tech industry is easy to gather around the University. This is because the high-tech industry is a combination of technology intensive and capital intensive industries. Under the catalysis of the financial factors, the enterprises in the high-tech zone will accelerate the development, thus driving the whole new area to gain the competitive advantage. The development of Financial Street and the promotion of scientific research ability of Chifeng University in Chifeng is bound to be one of the interaction, and on this basis, in a short period of time (10 years), Financial Street Chifeng can form the primary stage of science and Technology Industrial Park, that is, the high-tech zone of the prototype.

\section{The development idea of the High Tech Park of Chifeng University North Road}

Chifeng University in deepening reform, through the innovation of state-owned assets management system, scientific research personnel, scientific research equipment management and other new management system, you can be part of the college's laboratory and scientific research results in Financial Street market, capital operation, absorb the risk investment, research and promote the economic development of Chifeng's economic transformation and upgrading. Chifeng University can be nonferrous metals industry research results open sharing, for the development of Chifeng nonferrous metals deep processing industry to play professional expertise. In addition to mature about flower cultivation research projects and adjacent Rainbow Flower Market is more 
extensive and in-depth cooperation between colleges and enterprises, improve the Chifeng city infrastructure, agricultural system.

Chifeng College of the North Gate Street may be formed in the initial stage of science and technology industry area within the next five to ten years, high-tech zones in the prototype. Fifteen to twenty years to become a more mature college students in Chifeng City Park, the next twenty years, will become Chifeng city of science and Technology Innovation Park, high-tech achievements into the park, Chifeng City, research and production base. Chifeng City, as the economic development of the resource-based cities, to achieve economic transformation and upgrading and sound and fast development, we must now take Financial Street as an opportunity to create a new and effective talent introduction and management model, actively support the university scientific research workers, college students into scientific research enterprises, and vigorously promote the reform of the financial system, foster and develop the localization of high-tech industrial park, support innovative enterprises, so as to have more potential in the development of natural resources to support the development of Chifeng city.

To achieve the above objectives, the need for policy support, human resources, science and technology, capital injection, market operations and other elements of the common role. In the course of the transformation and development of Chifeng City, it is necessary to introduce and develop new and high technology talents, enterprises and industries from now on. In order to achieve the north gate of Chifeng University Financial Street to create a vision for high-tech industrial park.

\section{References}

[1] D.Y. Li, Chifeng industrial structure adjustment rationality and industrial development research, Journal of Chifeng University, 2007.06:42-43.

[2] J. Zhang, internal relations and development conception of Inner Mongolia's four league and the northeast, the Inner Mongolia Bureau of statistics, 2005.05.15

[3] J. Zhao, Chen Chuankang, China geography, higher education press, 2000.

[4] Kelly Chan, Zheng Dongzi, Huang Chenglin, human geography (Second Edition), 2007. 